\author{
Leila Zeinalzadeh AHRANJANI, PhD Candidate \\ E-mail: lzeinalzade@yahoo.com \\ Associate Professor Reza Kazemi MATIN, PhD \\ E-mail: rkmatin@ kiau.ac.ir (Corresponding author) \\ Department of Mathematics, Islamic Azad University \\ Karaj Branch, Karaj, Iran
}

\title{
TECHNICAL MEASURE OF CAPACITY UTILIZATION IN TWO- STAGE PRODUCTION SYSTEMS: A DATA ENVELOPMENT ANALYSIS APPROACH
}

\begin{abstract}
The primary aim of the present study is to consider the performance of two-stage production processes for estimating capacity utilization (CU). In short-run, capacity utilization relies on the capabilities of decision making units in employing fixed production factors. The production factors are being divided into fixed and variable inputs to not only measure but extend this indicator. Then, a modified network DEA model is used to measure the capacity utilization and investigate the intermediate products effects on CU. Finally, a numerical example is provided to indicate the applicability and effectiveness of the present model.

Keywords: Network Data Envelopment Analysis (NDEA); Fixed production factors; Capacity Utilization (CU); Intermediate product; Two-stage production process.
\end{abstract}

\section{JEL Classification: C61, C67}

\section{Introduction}

Data Envelopment Analysis (DEA) is a non-parametric technique introduced by Charnes et al. (1978) to measure relative efficiency of decision making units (DMUs). Generally, DMUs apply sets of inputs to produce sets of outputs.

In traditional DEA models, DMUs are regarded as black-boxes that transform initial inputs to final outputs. In many real situations the production processes are comprised of two or several sub-processes, therefore applying them almost always results in the internal structures negligence. Inevitably, these models are in urgent need of improvement to do reliable and precise assessment. Taking production systems' internal 
structures into consideration, network DEA models have been introduced; see Färe and Grosskopf (2000). Unlike previous models, network DEA models reflect the internal structure of units in performance evaluation. In recent years, various models have been developed to evaluate the efficiency of network production systems. For example, Kazemi Matin and Azizi (2014) presented a general novel approach for measuring the efficiency score of network production processes with arbitrary internal structures. Despotis et al. (2016) also offered a general network DEA method to estimate the efficiency of series multi-stage processes. Having offered a new approach based on multi-objective programming, they attempted to estimate the stage efficiency score in a very unique and unbiased way. Kao (2014) made a comprehensive review of all studies conducted on network DEA. Moreover, based on network structures, he made a category for network DEA models. According Kao study, numerous studies conducted network were based on two-stage processes. The twostage production processes could be defined as the simplest network systems which the outputs of the first stage (intermediate products/measures) are applied as the inputs of the second stage. Liang et al (2008) employed game theory concepts and developed the DEA methods to examine the efficiency of two-stage network systems. Both their model and Despotis et al. (2016)'s approach have recently been used by $\mathrm{Li}$ et al. (2018) to generate a Parato solution and identify the leader stage in network DEA. This method delineates that the optimal solution for the Chen et al.'s suggested model is also a leader-follower solution. Kao and Hwang (2008) proposed other method to measure the performance of two-stage systems and defined the overall efficiency of the system as the product of the two stages efficiencies. Likewise, Chen et al. (2009) proposed a distinct but somehow similar to Kao and Hwang's. The distinction of their model was having additive format. Their additive model can be used both in constant returns to scale (CRS) and variable returns to scale (VRS). Two models (Kao and Hwang, 2008 \& Chen et al., 2009) are based on the reasonable assumption that the weights employed for the intermediate measures are the same. The optimal solution of multiplicative decomposition approach (Kao and Hwang's model, 2008) and additive decomposition approach (Chen et al.'s model, 2009) may be non-unique and biased (Despotis et al., 2014).

Accordingly, Despotis et al. (2014) introduced a novel method to not only overcome shortcomings of previous models but also evaluate both 
individual and overall efficiencies of two-stage processes. Additionally, it relies on selection of an output orientation for the first stage and an input orientation for the second stage. Generally, two-stage DEA techniques are classified into four approaches: the standard DEA approach, the efficiency decomposition approach, the network DEA approach and the game theoretic approach (Cook et al., 2010). Unlike studies done in the banking industry, Boloori and Pourmahmoud (2016) have applied a more general method to evaluate this industry and modified it into a more precise structure within three processes in each bank branch. They obtained efficiency targets and extended an envelopment form of the network SBM model. Their introduced model is a developed version of Tone and Tsutsui's model.

Chen et al. (2015) applied a SBM-based model to extend the work of Tone and Tsutsui (2009). They developed two models (envelopment-based and multiplier-based) to achieve the frontier points (projections) for inefficient DMUs in two-stage processes. They also highlighted the equivalence in overall inefficiency of the system to the sum of inefficiencies of the two processes. Abundant studies on two-stage production systems show that this system possess significant and particular place in analyzing new modelling ideas in network production systems.

One of the most important topics in science management is the estimation of the capacity and capacity utilization (CU) in production systems. Capacity has been described as a firm capability to produce a potential output (Vestergaard et al., 2003). There are two capacity measures: technical and economic. Johansen (1968) provided capacity and CU's theoretical framework. Johansen $(1968$, p.68) has introduced the production function for defining the technical measure of single output capacity as, " the maximum amount that can be produced per unit of time exiting plant and equipment, provided the availability of variable factors of production is not restricted". The current study employs the technical concept of capacity output to measure the capacity utilization. Capacity utilization demonstrates the industry performance indicator which describes the relationship between the actual output -what is actually produced- and potential output -what could be produce-. Generally the capacity utilization means a proportion of potential capacity being used and typically measured as the ratio of actual output to capacity output. In recent years, some researches have focused on Johansen's definition and used the DEA methodology to estimate capacity 
output and CU's manufacturing firms. This approach was introduced as first by Fare (1984). His approach could be regarded the weaker version of the Johansen's due to the fact that outputs are bounded by fixed production inputs. Later, Fare et al. (1994) modified and developed this technique. They proposed an output-oriented measure of technical efficiency which could be used to calculate the capacity output and CU. The introduced measure of CU by Fare et al. (1984) may be biased downward (Fare et al., 1994). Fare et al.'s proposed model has been widely used in various sectors (Vestergaard et al., 2003, Zhang et al., 2016, Yu et al., 2016, Sahoo \& Tone (2009) and Yang \& Fukuyama, 2018). In order to introduce a non-radial CU measure, Cooper et al. (2006) presented and developed SBM model to measure these concepts. Their proposed technique has been utilized by Sahoo and Tone (2009) to investigate CU in Indian banks. A dynamic SBM-DEA model is introduced to define a dynamic CU measure and calculate the CU of China's industrial sector (Zhang et al., 2016). Yu et al (2016) have also been able to estimate the physical capacity utilization and cost gap between actual and global long-run minimum costs by applying an input-oriented SBM-DEA model. Their method is presented and illustrated on a real case study of 13 Low-cost carriers around the world for the year 2010. Recently, a new generalized CU indicator has been developed and defined as the difference between two directional distance functions by Yang and Fukuyama (2018). Their proposed indicator measures the amount of the utilization of the current variable inputs.

All the studies have widely used the traditional DEA models to assess capacity utilization of production systems. Indeed, they regarded production systems as single stage processes (black boxes) while we extend this concept in two-stage production systems and investigate effect of intermediate products of systems of CU Following a technological notion and developing non-parametric Fare et al.'s (1994) technique.

The remainder of the paper is organized as follows. The required background is represented in the next section. Determining $\mathrm{CU}$ scores in two-stage production systems is provided in section 3. A numerical example illustrates the applicability of the proposed model in section 4. Finally, conclusions are provided in section 5. 


\section{Preliminaries}

This section is devoted to brief introduction of Kao and Tone's model (2008) and concepts and models applied to measure CU.

It is significant to note that the radial DEA models are on the basis of the proportional change of input or output resources and commonly neglect the presence of slacks in the efficiency scores. The most fundamental radial models were introduced by Charnes et al.(1978) and Banker et al. (1984) which called CCR and BCC models, respectively. These models have been generally used to calculate efficiency scores of production systems.

\subsection{The radial models}

Let's consider a set of n DMUs denoted by $D M U_{j}(j=1, \ldots, n)$, consuming $\mathrm{m}$ inputs to produce s outputs. The observed input and output vectors of $D M U_{j}$ are denoted by $X_{j}=\left(x_{1 j}, x_{2 j}, \ldots, x_{m j}\right)$ and $Y_{j}=\left(y_{1 j}, y_{2 j}, \ldots, y_{s j}\right)$, respectively. Also, let's suppose that all of the inputs and outputs are nonnegative. Traditional DEA model which measures the efficiency score of $\mathrm{DMU}_{k}$ under VRS assumption, is BCC (Banker-Charnes-Cooper) model that was presented by Banker et al. (1984):

$$
\begin{aligned}
& E_{k}=\max \frac{\boldsymbol{u}^{T} y_{k}+\boldsymbol{u}_{k}}{\boldsymbol{v}^{T} x_{k}} \\
& \text { s.t. } \frac{\boldsymbol{u}^{T} y_{j}+\boldsymbol{u}_{k}}{\boldsymbol{v}^{T} x_{j}} \leq 1, \quad j=1, \ldots, n \\
& \boldsymbol{v}, \boldsymbol{u} \geq 0, \quad \boldsymbol{u}_{k} \text { free }
\end{aligned}
$$

Model (1) is a fractional program which can easily transform into an equivalent linear form (Charnes and Cooper (1962). Envelopment (dual) model of the above BCC model is introduced as follows (Banker et al., 1984):

$\min \theta_{k}$

$$
\begin{array}{rl}
\text { s.t } \sum_{j=1}^{n} \lambda_{j} x_{i j} \leq \theta_{k} x_{i k} & i=1, \ldots, m \\
\sum_{j=1}^{n} \lambda_{j} y_{r j} \geq y_{r k} & r=1, \ldots, s
\end{array}
$$


Leila Zeinalzadeh Ahranjani, Reza Kazemi Matin

$$
\begin{aligned}
& \sum_{j=1}^{n} \lambda_{j}=1 \\
& \lambda_{j} \geq 0 \quad j=1, \ldots, n
\end{aligned}
$$

Where $\lambda_{j}$ is the intensity variable. It should be noticed that among input resources for production, some of them are fixed and unchangeable during a production period (e.g., plant and equipment) whereas some other inputs could be precisely managed by the manufacturing firms in the short-run; (e.g., number of employees, working hours and days). Former inputs are called fixed $\left(x^{F}\right)$ and latter ones are called inputs variable $\left(x^{V}\right)$. It goes without saying that all the inputs can be altered in the long-run. According to aforementioned subjects, the inputs are categorized into $k$ fixed inputs not being able to alter in the short-run and $(m-k)$ variable inputs. The output-oriented of the above BCC model (BCC-O) is presented as follows:

$$
\begin{array}{llc}
\varphi_{o}^{*}= & \max \varphi_{o} & \\
\text { s.t } & \sum_{j=1}^{n} \lambda_{j} x_{i j}^{F} \leq x_{i o}^{F} & i=1, \ldots, k \\
& \sum_{j=1}^{n} \lambda_{j} x_{i j}^{V} \leq x_{i o}^{V} & i=k+1, \ldots, m \\
& \sum_{r=1}^{s} \lambda_{j} y_{r j} \leq \varphi_{o} y_{r o} & r=1, \ldots, s \\
& \sum_{j=1}^{n} \lambda_{j}=1 & \\
& \lambda_{j} \geq 0 & j=1, \ldots, n
\end{array}
$$

The output-oriented DEA models allow determining the maximum radial extension of outputs given the existing levels of inputs. The traditional BCC models are applicable for systems as black boxes which some inputs are consumed to produce some outputs. Hence, they are not efficient enough to evaluate the efficiency of systems especially in two-stage (network) production processes due to overestimate on of the overall efficiency scores, (Kao \& Hwang, 2008).

\subsection{Two-stage production systems}

Consider a two-stage structure as shown in Fig.1. In this structure the outputs from the first stage are seen as intermediate measures which constitute all inputs to the second stage. Also, $z_{d k}$ is indicated as $d^{\text {th }}$ intermediate product, $\mathrm{d}=$ $1, \ldots, q$, of $D M U_{k}$. Furthermore, all data are positive, i.e. $X_{i}, Z_{d}$ and $Y_{r}>0$ for all possible $i=1, \ldots, m ; d=1, \ldots, q$ and $r=1, \ldots, s$. 


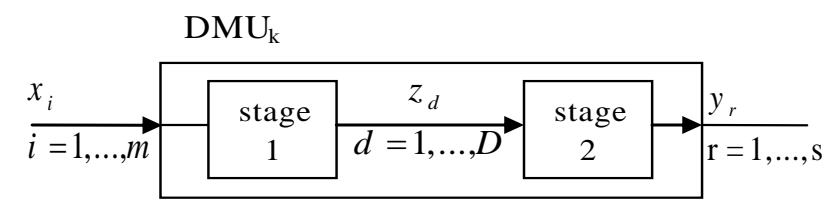

Figure 1. Two stage system

Kao and Hwang [7] presented following model to assess efficiency score of twostage systems more precisely than the other traditional models such as CCR and BCC model. The output-oriented of this model in two-stage systems is presented as follow:

$$
\begin{aligned}
& \min \varphi_{k} \\
& \text { s.t. } \quad \sum_{j=1}^{n} \lambda_{j} x_{i j} \leq x_{i k} \\
& i=1, \ldots, m \\
& \sum_{j=1}^{n} \mu_{j} \quad y_{r j} \geq \varphi_{k} y_{r k} \\
& r=1, \ldots, s \\
& \sum_{j=1}^{n}\left(\lambda_{j}-\mu_{j}\right) z_{d j} \geq 0 \\
& d=1, \ldots, D \\
& \sum_{j=1}^{n} \lambda_{j}=1 \\
& \sum_{j=1}^{n} \mu_{j}=1 \\
& \lambda_{j}, \mu_{j} \geq 0 \quad j=1, \ldots, n
\end{aligned}
$$

Here $\lambda_{j}$ and $\mu_{j}$ are the intensity weights of each are stage. Suppose that $\varphi^{*}$ is the optimal value of model (3). $\varphi^{*}>1$ means that the $D M U_{O}$ Can expand all outputs, employing the all current inputs (fixed and variable). We will benefit from this model to estimate capacity utilization in DEA framework.

\subsection{Technical measure of capacity utilization}

The technical measure of capacity is a short-run concept of performance proposed by Johansen (1968) that relies on the capabilities of firms in using fixed production factors to produce a potential output. On this basis, inputs be divided as fix $\left(x^{f}\right)$ and variable $\left(x^{v}\right)$; i.e. $x=\left(x^{f}, x^{v}\right)$, for each unit. Now, to estimate and introduce radial measure of capacity output, Fare et al. (1994) applied the outputoriented radial model and then assumed DMUs evaluate to many variable inputs needed for full capacity (consistent with Johansen's definition). Hence, 
corresponding restrictions of variable inputs are omitted and following model introduced as:

$$
\begin{array}{lll}
\varphi_{o}^{\mathrm{F}}= & \max \varphi_{o} & \\
\text { s.t } & \sum_{j=1}^{n} \lambda_{j} x_{i j}^{F} \leq x_{i o}^{F} \quad & i=1, \ldots, k \\
& \sum_{r=1}^{s} \lambda_{j} y_{r j} \leq \varphi_{o} y_{r o} & \\
& \sum_{j=1}^{n} \lambda_{j}=1 & \\
& \lambda_{j} \geq 0 & j=1, \ldots, s
\end{array}
$$

In fact Fare et al. (1994) argued that a more proper and unbiased CU measure is the technically efficient output level ratio to the capacity output level. Assume that $\varphi_{o}^{*}$ and $\varphi_{o}^{* \mathrm{~F}}$ are optimal values obtained by models (2) and (4) respectively, so technical measure of $\mathrm{CU}$ is defined and computed by following equation (Fare et al., 1994):

$$
C U=\frac{\varphi_{o}^{*}}{\varphi_{o}^{* \mathrm{~F}}}
$$

Recent relation shows that the value of capacity utilization can be no greater than 1. It implies whether a DMU has the potential for greater production with the existing fixed inputs. If this value is less than 1 (e.g., 0.80), it shows that approximately A\% (e.g., 80\%) of the capacity output could be obtained through improvement in technical efficiency. The remaining increase in output (e.g., 20\%) would require extension of the variable inputs. Note that this measure is calculated the gap between actual and capacity output. This gap is created particularly by inefficient utilization of the fixed inputs. However, when technical inefficiency exists, part of the output gap is produced through inefficient utilization of variable inputs.

Fare et al (1994) also proposed the recent relation, under the CRS assumption, applying the CCR (CCR-O) model. It was named the plant capacity utilization measure of the under evaluation unit $D M U_{o}$. In fact Fare et al (1994) argue that a more proper $\mathrm{CU}$ measure is the technically efficient output level ratio to the capacity output level.

\section{DEA estimation of technical capacity utilization in two-stage production systems}

Suppose that all of DMUs have the two-stage structure and extend the concept of CU for these systems. To measure each DMU's capacity output with the 
existing fixed inputs whose variable inputs are not considered in evaluating the performance i.e. these inputs are not restricted, the following model is proposed:

$$
\begin{aligned}
& \varphi_{F}^{*}= \max \varphi_{F} \\
& \text { s.t } \quad \sum_{j=1}^{n} \lambda_{j} x_{i j}^{F} \leq x_{i o}^{F} \quad i=1, \ldots, k \\
& \sum_{j=1}^{n}\left(\lambda_{j}-\mu_{j}\right) z_{q j}=0 \quad q=1, \ldots, p \\
& \sum_{j=1}^{n} \mu_{j} y_{r j} \leq \varphi_{F} y_{r o} \quad r=1, \ldots, s \\
& \sum_{j=1}^{n} \lambda_{j}=1 \\
& \sum_{j=1}^{n} \mu_{j}=1 \\
& \lambda_{j}, \mu_{j}, s_{r}^{+} \geq 0 \quad j=1, \ldots, n ; r=1, \ldots, s
\end{aligned}
$$

The main difference between two models ((3) and (5)) is the treatment of variable inputs. In model (5), it is assumed that the DMU has availability to many variable inputs required for full capacity, consequently; their corresponding restrictions are omitted from model. We assume that $\varphi^{*}$ and $\varphi_{F}^{*}$ are the optimal value of models (3) and (5) respectively, by definition, the technical capacity utilization in two-stage systems can be calculated as follows:

$$
C U\left(y, z, x^{F}, x^{V}\right)=\frac{\varphi^{*}}{\varphi_{F}^{*}}
$$

It is quite obvious that $C U \leq 1$. Note also that the cu amount is closer to 1 then the importance of variable inputs will be less in the performance assessment. In other words, variable inputs have less effect on the performance of two-stage systems. The introduced measure lacks of any technical inefficiency. In other words it is not downward biased.

\section{Case study}

In this section, a real data set is applied to illustrate the results of the new proposed approach. The proposed method is used to 27 firms in the banking industry in US originally studied in Chen and Zhu (2004). They introduced a twostage structure with three inputs, one intermediate measure and two final outputs where the number of employees indicates the only variable input and fixed elements are IT investment and fixed assets. Fig. 2 provides a graphic of the structure of a two-stage DMU in the banking industry. 
Leila Zeinalzadeh Ahranjani, Reza Kazemi Matin

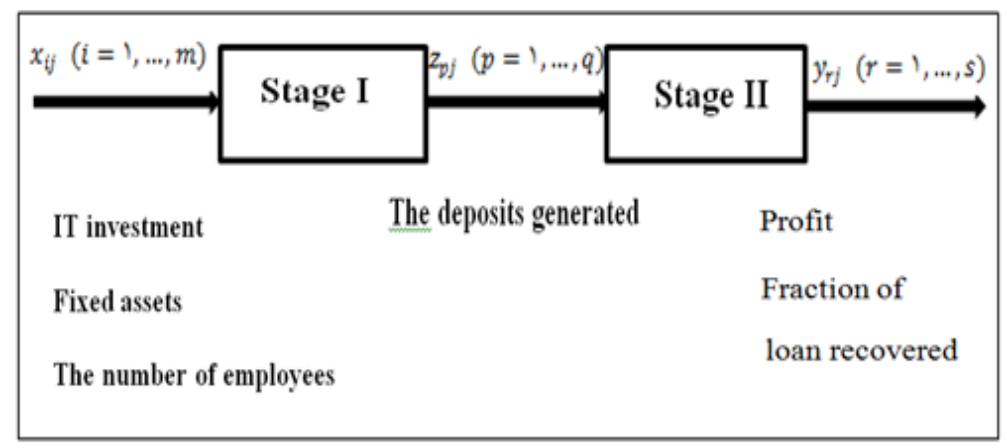

Figure 2: Two-stage structure of bank

The inputs, intermediate measure and outputs of these firms are indicated in table 1.

Table 1: Data of 27 US banks.

\begin{tabular}{|l|l|l|l|l|l|l|}
\hline DMUs & $\begin{array}{c}\boldsymbol{x}_{\mathbf{1}} \\
\text { (\$billions) }\end{array}$ & $\begin{array}{c}\boldsymbol{x}_{\mathbf{2}} \\
(\mathbf{\$} \text { billions) }\end{array}$ & $\begin{array}{c}\boldsymbol{x}_{\mathbf{3}} \\
\text { (thousands) }\end{array}$ & $\begin{array}{c}\mathbf{z} \\
\text { (\$billions) }\end{array}$ & $\begin{array}{c}\boldsymbol{y}_{\mathbf{1}} \\
\text { (\$billions) }\end{array}$ & $\begin{array}{c}\boldsymbol{y}_{\mathbf{2}} \\
\text { (\$billions) }\end{array}$ \\
\hline$D M U_{1}$ & 0.150 & 0.713 & 13.3 & 14.478 & 0.232 & 0.986 \\
\hline$D M U_{2}$ & 0.170 & 1.071 & 16.9 & 19.502 & 0.340 & 0.986 \\
\hline$D M U_{3}$ & 0.235 & 1.224 & 24.0 & 20.952 & 0.363 & 0.986 \\
\hline$D M U_{4}$ & 0.211 & 0.363 & 15.6 & 13.902 & 0.211 & 0.982 \\
\hline$D M U_{5}$ & 0.133 & 0.409 & 18.485 & 15.206 & 0.237 & 0.984 \\
\hline$D M U_{6}$ & 0.497 & 5.846 & 56.42 & 81.186 & 1.103 & 0.955 \\
\hline$D M U_{7}$ & 0.060 & 0.918 & 56.42 & 81.186 & 1.103 & 0.986 \\
\hline$D M U_{8}$ & 0.071 & 1.235 & 12.0 & 11.441 & 0.199 & 0.985 \\
\hline$D M U_{9}$ & 0.500 & 18.120 & 89.51 & 124.072 & 1.858 & 0.972 \\
\hline$D M U_{10}$ & 0.120 & 1.821 & 19.8 & 17.425 & 0.274 & 0.983 \\
\hline$D M U_{11}$ & 0.120 & 1.915 & 19.8 & 17.425 & 0.274 & 0.983 \\
\hline$D M U_{12}$ & 0.050 & 6.918 & 13.1 & 14.342 & 0.177 & 0.985 \\
\hline$D M U_{13}$ & 0.370 & 4.432 & 12.5 & 32.491 & 0.648 & 0.945 \\
\hline$D M U_{14}$ & 0.440 & 4.504 & 41.9 & 47.653 & 0.639 & 0.979 \\
\hline$D M U_{15}$ & 0.431 & 1.241 & 41.1 & 52.630 & 0.741 & 0.981 \\
\hline$D M U_{16}$ & 0.110 & 5.892 & 14.4 & 17.493 & 0.243 & 0.988 \\
\hline$D M U_{17}$ & 0.053 & 0.973 & 7.6 & 9.512 & 0.067 & 0.980 \\
\hline$D M U_{18}$ & 0.345 & 0.444 & 15.5 & 42.469 & 1.002 & 0.948 \\
\hline$D M U_{19}$ & 0.128 & 0.508 & 12.6 & 18.987 & 0.243 & 0.985 \\
\hline$D M U_{20}$ & 0.055 & 0.370 & 5.6 & 7.546 & 0.153 & 0.987 \\
\hline
\end{tabular}


Technical Measure of Capacity Utilization in Two-Stage Production Systems

\begin{tabular}{|l|l|l|l|l|l|l|}
\hline$D M U_{21}$ & 0.057 & 0.395 & 5.7 & 7.595 & 0.123 & 0.987 \\
\hline$D M U_{22}$ & 0.098 & 2.680 & 14.1 & 16.906 & 0.233 & 0.981 \\
\hline$D M U_{23}$ & 0.104 & 0.781 & 14.6 & 17.264 & 0.263 & 0.983 \\
\hline$D M U_{24}$ & 0.206 & 0.872 & 19.6 & 36.430 & 0.601 & 0.982 \\
\hline$D M U_{25}$ & 0.067 & 1.757 & 10.5 & 11.581 & 0.120 & 0.987 \\
\hline$D M U_{26}$ & 0.100 & 0.713 & 12.1 & 22.207 & 0.248 & 0.972 \\
\hline$D M U_{27}$ & 0.0106 & 0.713 & 12.7 & 20.670 & 0.253 & 0.988 \\
\hline
\end{tabular}

As mentioned in previous section, we first employ models (3) and (5) to calculate the maximum output with all inputs (fixed and variable) and capacity output of each DMU with only fixed inputs respectively. In order to determine of CU value, Assume that $\varphi^{*}$ and $\varphi_{F}^{*}$ be the optimal value of models (3) and (5) respectively. Then, each DMU's CU is obtained by applying formula (6). Table 2 illustrates the estimated CU for each of these DMUs in two different cases (twostage and black box).It is significant to note that in the black box position, the intermediate measures are disregarded. In this case, the systems are considered as one-stage production processes that convert inputs to outputs.

Table 2: CU scores of 27 banks in two different positions: (Black box and Two-stage)

\begin{tabular}{|c|c|c|c|c|c|c|}
\hline DMUs & $\begin{array}{c}\left(\boldsymbol{\varphi}^{*}\right) \\
\text { Two- } \\
\text { Stage }\end{array}$ & $\begin{array}{c}\left(\boldsymbol{\varphi}_{\boldsymbol{F}}^{*}\right) \\
\text { Two- } \\
\text { Stage }\end{array}$ & $\begin{array}{c}\boldsymbol{C U}=\left(\boldsymbol{\varphi}^{*} / \boldsymbol{\varphi}_{\boldsymbol{F}}^{*}\right) \\
\text { Two-stage }\end{array}$ & $\begin{array}{c}\left(\boldsymbol{\varphi}^{*}\right) \\
\text { Black- } \\
\text { box }\end{array}$ & $\begin{array}{c}\left(\boldsymbol{\varphi}_{\boldsymbol{F}}^{*}\right) \\
\text { Black- } \\
\text { box }\end{array}$ & $\begin{array}{c}\boldsymbol{C U}=\left(\boldsymbol{\varphi}^{*} / \boldsymbol{\varphi}_{\boldsymbol{F}}^{*}\right) \\
\text { Black- box }\end{array}$ \\
\hline$D M U_{1}$ & 1.002028 & 1.002028 & 1.000000 & 1.00203 & 1.00203 & 1.00000 \\
\hline $\boldsymbol{D M U _ { \mathbf { 2 } }}$ & 1.001819 & 1.001819 & $\mathbf{1 . 0 0 0 0 0 0}$ & 1.00167 & 1.00182 & $\mathbf{0 . 9 9 9 8 6}$ \\
\hline$D M U_{3}$ & 1.001764 & 1.001764 & 1.000000 & 1.00176 & 1.00176 & 1.00000 \\
\hline$D M U_{4}$ & 1.005697 & 1.005697 & 1.000000 & 1.00000 & 1.00000 & 1.00000 \\
\hline$D M U_{5}$ & 1.004065 & 1.004065 & 1.000000 & 1.00205 & 1.00205 & 1.00000 \\
\hline $\boldsymbol{D M} \boldsymbol{U}_{\mathbf{6}}$ & 1.031780 & 1.031780 & $\mathbf{1 . 0 0 0 0 0 0}$ & 1.03043 & 1.03178 & $\mathbf{0 . 9 9 8 6 9}$ \\
\hline$D M U_{\mathbf{7}}$ & 1.000000 & 1.000000 & 1.000000 & 1.00000 & 1.00000 & 1.00000 \\
\hline $\boldsymbol{D M} \boldsymbol{U}_{\mathbf{8}}$ & 1.003046 & 1.003046 & $\mathbf{1 . 0 0 0 0 0 0}$ & 1.00295 & 1.00305 & $\mathbf{0 . 9 9 9 9 0}$ \\
\hline$D M U_{9}$ & 1.000000 & 1.000000 & 1.000000 & 1.00000 & 1.00000 & 1.00000 \\
\hline$D M U_{10}$ & 1.005033 & 1.005033 & 1.000000 & 1.00503 & 1.00503 & 1.00000 \\
\hline$D M U_{11}$ & 1.005033 & 1.005033 & 1.000000 & 1.00503 & 1.00503 & 1.00000 \\
\hline$D M U_{12}$ & 1.003046 & 1.003046 & 1.000000 & 1.00305 & 1.00305 & 1.00000 \\
\hline $\boldsymbol{D M} \boldsymbol{U}_{\mathbf{1 3}}$ & 1.026425 & 1.044447 & $\mathbf{0 . 9 8 2 7 4 5}$ & 1.02152 & 1.04445 & $\mathbf{0 . 9 7 8 0 5}$ \\
\hline$D M U_{14}$ & 1.008253 & 1.008253 & 1.000000 & 1.00825 & 1.00825 & 1.00000 \\
\hline$D M U_{15}$ & 1.005955 & 1.005955 & 1.000000 & 1.00596 & 1.00596 & 1.00000 \\
\hline$D M U_{16}$ & 1.000000 & 1.000000 & 1.000000 & 1.00000 & 1.00000 & 1.00000 \\
\hline $\boldsymbol{D M} \boldsymbol{U}_{\mathbf{1 7}}$ & 1.007573 & 1.008163 & $\mathbf{0 . 9 9 9 4 1 4}$ & 1.00743 & 1.00816 & $\mathbf{0 . 9 9 9 2 7}$ \\
\hline
\end{tabular}


Leila Zeinalzadeh Ahranjani, Reza Kazemi Matin

\begin{tabular}{|l|l|l|l|l|l|l|}
\hline$D M U_{18}$ & 1.000000 & 1.000000 & 1.000000 & 1.00000 & 1.00000 & 1.00000 \\
\hline$D M U_{19}$ & 1.003046 & 1.003046 & 1.000000 & 1.00227 & 1.00227 & 1.00000 \\
\hline$D M U_{20}$ & 1.000000 & 1.000000 & 1.000000 & 1.00000 & 1.00000 & 1.00000 \\
\hline $\mathbf{D} \boldsymbol{M} \boldsymbol{U}_{\mathbf{2 1}}$ & 1.000031 & 1.000358 & $\mathbf{0 . 9 9 9 6 7 3}$ & 1.00001 & 1.00007 & $\mathbf{0 . 9 9 9 9 4}$ \\
\hline$D M U_{22}$ & 1.007136 & 1.007136 & 1.000000 & 1.00714 & 1.00714 & 1.00000 \\
\hline$D M U_{23}$ & 1.005059 & 1.005059 & 1.000000 & 1.00506 & 1.00506 & 1.00000 \\
\hline $\mathbf{D M} \boldsymbol{U}_{\mathbf{2 4}}$ & 1.003961 & 1.005269 & $\mathbf{1 . 0 0 0 0 0 0}$ & 1.00000 & 1.00527 & $\mathbf{0 . 9 9 4 7 6}$ \\
\hline $\boldsymbol{D M} \boldsymbol{U}_{\mathbf{2 5}}$ & 1.001013 & 1.001013 & $\mathbf{1 . 0 0 0 0 0 0}$ & 1.00070 & 1.00101 & $\mathbf{0 . 9 9 9 6 9}$ \\
\hline$D M U_{26}$ & 1.016461 & 1.016461 & 1.000000 & 1.01616 & 1.01646 & 1.00000 \\
\hline$D M U_{27}$ & 1.000000 & 1.000000 & 1.000000 & 1.00000 & 1.00000 & 1.00000 \\
\hline
\end{tabular}

The comparison of obtained $\mathrm{CU}$ scores from the two different positions leads to following conclusions. According to table (2), due to taking or ignoring the intermediate measures, the CU value for special DMU is not necessarily the same in the both positions. For example consider $D M U_{24}$, regarding the assessment of this unit in two-stage position $C U=1$ i.e., even with employing the current fixed inputs it is unable to produce more output whereas if it is analyzed in black box form, its $\mathrm{CU}$ is less than 1 and has excess capacity in black box position. Namely this firm possesses a potential to produce more output with the current fixed inputs. So, what is clear is that taking the intermediate products or their negligence affects the firm's ability to access certain outputs levels.

The received results of table 2 in two-stage position show that only three of all DMUs would not operate with full capacity. These DMUs (13, 17, and 21) don't fully utilize their fixed inputs and so, their corresponding CU is estimated less than 1 . Therefore, they could increase their outputs without alternation in level of fixed inputs. Note that insufficient employees results to low CU.

To check the results of table 2, we calculate the $\mathrm{CU}$ score of $\mathrm{DMU}_{13}$. Using models (3) and (5), in the evaluation of this firm, the following optimal values are obtained

$\varphi^{*}=1.026425 \quad$ and $\quad \varphi_{F}^{*}=1.044447$

Applying relation (5), we compute its corresponding CU as follows:

$C U_{D M U_{14}}=\frac{\varphi^{*}}{\varphi_{F}^{*}}=\frac{1.026425}{1.044447}=0.982745 \cong 0.98$ or $98 \%$

Since $C U_{D M U_{14}}<1$ then it has excess capacity and could produce more than its current levels. In other words, this measure indicates that there is a possibility to 
Technical Measure of Capacity Utilization in Two-Stage Production Systems

improve its production by $2 \%$ without additional fixed inputs such as the hiring new employees. Similar analyses can be carried out for other firms (DMUs).

\section{Conclusion}

The traditional DEA models consider the production systems as single stage in which the evaluation performance is exclusively effective in external inputs and final outputs. Accordingly, inaccuracy is always the inevitable drawback in the achieved efficiency scores. In recent years, network DEA models are extensively suggested to assess and study the internal structures. The present study come up with the estimation of the capacity utilization measure in two-stage production system using radial network DEA model. The ability of DMUs determines the degree of capacity utilization in the short-run, for this reason the factors of production are classified into fixed and variable inputs. The radial network DEA model is introduced to develop the Fare et al.'s work. We took the assessment of service systems including banks by using proposed method.

Numerical example is involved in black box and two-stage positions to assert the effect of intermediate measures on CU scores. Then the model is used to compare the results with Fare et al.'s approach (classical DEA model). Since they either take or neglect the intermediate measures, therefore the estimated CU scores for some of DMUs were not necessarily the same in the both positions. Moreover, it should be highlighted that the DMUs which their corresponding CU is less than 1 , do not fully utilize their inputs and there is a possibility to improve the outputs without adding current fixed inputs as well. Ultimately, the results both demonstrate intermediate measures effect and reflects firms' thoughts on interpolation decision making. The future researches could cover the development of fuzzy and stochastic version of the proposed model. In addition, the application to negative data model could be the other optimal subject for future research.

\section{REFERENCES}

[1] Banker, R.D., Charnes, A. \& Cooper, W.W. (1984), Some Models for Estimating Technical and Scale Inefficiencies in Data Envelopment Analysis. Management science, 30(9), 1078-1092;

[2] Boloori, F, Pourmahmoud, J. (2016), A Modified SBM-NDEA Approach for the Efficiency Measurement in Bank Branches. Oper Res Int. J 16, 301-326;

[3] Charnes, A, Cooper, W.W. (1962), Programming with Linear Fractional

Functional. Naval Research Logistics Quarterly, 9, 181-185;

[4] Charnes, A, Cooper, W.W, Rhodes, E. (1978), Measuring the Efficiency of

Decision Making Units. European Journal of Operational Research 2, 429-444; 
Leila Zeinalzadeh Ahranjani, Reza Kazemi Matin

[5] Chen, Y, Cook, W.D, Li, N, Zhu, J. (2009), Additive Efficiency

Decomposition in Two-Stage DEA. European Journal of Operational Research

196, 1170-1176;

[6] Chen, Y, Yongjun, L, Liang, L, Ahti, S, Huaqing , W. (2015), Frontier

Projection and Efficiency Decomposition in Two-Stage Processes with Slacks-

Based Measures. European Journal of Operational Research, 1-12;

[7] Cook, W.D, Liang, L, Zhu, J. (2010), Measuring Performance of Two-Stage

Network Structures by DEA: A Review and Future Perspective. Omega 38 (6),

423-430;

[8] Cooper, W.W, Seiford, L.M, Tone, K. (2006), Data Envelopment Analysis: A Comprehensive Text with Models, Applications, References and DEA Solver Software. Springer-Verlag New York, Inc.;

[9] Despotis, D K, Koronakos, G, Sotiros. D. (2014), Composition versus

Decomposition in Two-Stage Network DEA: A Reverse Approach. Journal of Productivity Analysis, 45(1): 71-87;

[10] Despotis, D K, Sotiros, D, Koronakos, G. (2016), A Network DEA

Approach for Series Multi-Stage Processes. Omega, 61:35-48;

[11] R. Färe, R. (1984), The Existence of Plant Capacity. Int. Econ. Rev. 25 (1),

209-213;

[12] Färe, R, Grosskopf, S. (2000), Network DEA. Socio-Economic Planning

Sciences, 34, 35-49;

[13] Färe, R, Grosskopf, S. (1994), C.A.K. Lovell, Production Frontiers.

Cambridge University Press, Cambridge, U.K;

[14] Johansen, L. (1968), Production Functions and the Concept of Capacity. In:

Recent research on the function of production. Namur, France: Namur University

Center for Study and Research;

[15] Kao, C. (2014), Network Data Envelopment Analysis: A Review. European Journal of Operational Research 239, 1-16;

[16] Kao, C, Hwang, S-N. (2008), Efficiency Decomposition in Two-Stage Data

Envelopment Analysis: An Application to Non-Life Insurance Companies in

Taiwan. European Journal of Operational Research 185, 418-429;

[17] Kazemi Matin, R, Azizi, R. (2014), A Unified Network-DEA Model for

Performance Measurement of Production Systems. Measurement 60, 186-193;

[18] Li, H, Chen, C, Cook,W.D, Zhang, J, Zho, J. (2018), Two-Stage Network

DEA: Who Is the Leader. Omega, 74, 15-19;

[19] Liang, L, Cook, W.D, Zhu, J. (2008), DEA Models for Two-Stage

Processes: Game Approach And Efficiency Decomposition. Naval Research

Logistics (NRL) 55, 643-653;

[20] Sahoo, B.K, Tone, K. (2009), Decomposing Capacity Utilization in Data

Envelopment Analysis: An Application to Banks in India. European Journal of

Operational Research 195, 575-594;

[21] Tone, K. Tsutsui, M. (2009) Network DEA: A Slacks-Based Measure

Approach. European Journal of Operational Research, 197, 243-252. 
Technical Measure of Capacity Utilization in Two-Stage Production Systems

[22] Vestergaard, N. Squires, D. Kirkley, J. (2003), Measuring Capacity and Capacity Utilization in Fisheries: The Case of the Danish Gill-Net Fleet. Fisheries Research 60,357-368;

[23] Yang, G.L. Fukuyama, H. (2018), Measuring the Chinese Regional Production using a Generalized Capacity Utilization Indicator. Omega 76, 112127 ;

[24] Yu, M-M. Chang, Y-C. Chen, L-H. (2016), Measurement of Airlines' Capacity Utilization and Cost Gap: Evidence From Low-Cost Carriers. Journal of air transport Management 53, 186-198;

[25] Zhang, S. Chang, T.P. Jiang, W. (2016), Dynamic Capacity Utilization in China's Industrial Sector. The Empirical Economics Letters, 15(6), 593-599. 